\title{
VIGOR DE SEMENTES DE RÚCULA E DESEMPENHO DAS PLANTAS EM CAMPO ${ }^{1}$
}

\author{
MAELI RAYANNE DA SILVA DANTAS², SALVADOR BARROS TORRES ${ }^{3}$
}

\begin{abstract}
RESUMO - A pesquisa foi realizada com o objetivo de avaliar a relação entre o potencial fisiológico de lotes de sementes de rúcula e o desempenho das plantas em campo. Para isso, duas cultivares de rúcula (Cultivada e Folha Larga), cada uma delas representada por quatro lotes de sementes, foram inicialmente avaliadas pelos testes de germinação, primeira contagem de germinação, classificação do vigor de plântulas, condutividade elétrica, envelhecimento acelerado, deterioração controlada e emergência de plântulas, utilizando-se o delineamento inteiramente casualizado, separadamente para cada cultivar e teste. $\mathrm{O}$ experimento de campo foi conduzido mediante semeadura direta, com cada unidade experimental constituída por seis linhas, e estas contendo dez plantas cada. O espaçamento utilizado foi de $0,2 \mathrm{~m}$ entre linhas e de $0,1 \mathrm{~m}$ entre plantas, com área total de 1,2 $\mathrm{m}^{2}$. Aos 15, 22, 30 e 36 dias após a semeadura, foram coletadas, ao acaso, amostras de 10 plantas por parcela, para a determinação da altura de plantas, do número médio de folhas e da massa da matéria seca da parte aérea da planta. O delineamento experimental foi o de blocos ao acaso, testando separadamente os efeitos dos lotes e cultivares. Diante dos resultados, concluiu-se que variações estreitas do vigor de lotes de sementes de rúcula com germinação superior à mínima estabelecida para comercialização não são suficientes para influenciar significativamente o desempenho das plantas em campo sob condições favoráveis.
\end{abstract}

Termos para indexação: Eruca sativa, potencial fisiológico, produção.

\section{SALAD ROCKET SEED VIGOR AND PLANT FIELD PERFOMANCE}

\begin{abstract}
The objective of the research was to evaluate the relationship between the physiological potential of different rocket seed lots and field plant performance. Two salad rocket cultivars (Cultivada and Folha Larga), each one represented by four seed lots, were initially evaluated by the germination, seedling vigor classification, electrical conductivity, accelerated ageing, controlled damage and seedling emergence tests; treatments (seed lots) were distributed separately in a completely randomized design for each cultivar and seed test. The field experiment was sowed directly; each experimental unit consisted of six rows with ten plants each; spacing was $0.2 \mathrm{~m}$ between rows and $0.1 \mathrm{~m}$ between plants, with an area of $1.2 \mathrm{~m}^{2}$, in a randomized blocks' design. At 15, 20, 30 and 36 days after sowing, samples of 10 plants per plot were randomly collected to determine plant height, average leaf number and shoot dry matter. Small variations in physiological potential among seed lots are not sufficient to affect plant field performance at favorable condutions.
\end{abstract}

Index terms: Eruca sativa, physiological potential, yield.

\footnotetext{
${ }^{1}$ Submetido em 23/03/2010. Aceito para publicação em 25/07/2010. Parte da Dissertação de Mestrado do primeiro autor apresentada ao Programa de Pós-graduação em Fitotecnia da UFERSA.
}

${ }^{2}$ Eng. Agrônomo, M.Sc., Técnica do IDIARN, Rua Aureliano Lobo, s/n,
Centro, 59650-970, Assu/RN, maeliray@hotmail.com.

${ }^{3}$ Eng. Agrônomo, Dr., Pesquisador da EMPARN e Prof. Colaborador do Departamento de Ciências Vegetais, UFERSA, Caixa Postal 137, 59625 900, Mossoró/RN, sbtorres@ufersa.edu.br 


\section{INTRODUÇÃO}

A rúcula (Eruca sativa L.) é uma hortaliça da família das Brassicaceae, originária do Mediterrâneo e da Ásia Ocidental. Apesar de ser produzida melhor sob temperaturas amenas, essa olerácea tem sido cultivada ao longo do ano, em diversas regiões do país (Filgueira, 2008).

A alta qualidade de sementes de hortaliças é de grande importância, principalmente quanto à germinação uniforme, necessária para garantir um estande ideal de plantas. Neste contexto, sementes de alto vigor se constituem em elemento básico e fundamental (Mendonça et al., 2003).

Os testes mais específicos para avaliar o vigor de sementes de hortaliças são representados pela deterioração controlada e a condutividade elétrica, mas há necessidade da obtenção de informações mais amplas sobre o assunto. No caso de rúcula, a avaliação do vigor de sementes tem sido restrita, principalmente em nossas condições. O exame da literatura indica que Ramos et al. (2004) destacaram a eficiência do teste de envelhecimento acelerado a $41{ }^{\circ} \mathrm{C}$ durante 48 horas, com o uso de água ou de solução saturada de $\mathrm{NaCl}$. Já Goulart e Tillmann (2007) verificaram que o teste de deterioração controlada $(24 \%$ de água $/ 41{ }^{\circ} \mathrm{C} / 24 \mathrm{~h}$ ) apresentou sensibilidade para avaliação do potencial fisiológico de sementes de rúcula e que o teste de envelhecimento acelerado tradicional $\left(41{ }^{\circ} \mathrm{C} / 48\right.$ h) e classificação do vigor de plântulas são indicações promissoras para essa finalidade. No tocante ao teste de condutividade elétrica, Alves e Sá (2009), informaram que este teste conduzido a $25{ }^{\circ} \mathrm{C}$, durante quatro horas, utilizando 50 sementes em $50 \mathrm{~mL}$ de água foi eficiente na separação de lotes de sementes de rúcula.

No que se refere às relações entre o vigor das sementes e o desempenho das plantas em campo também não estão suficientemente esclarecidas. Segundo TeKrony e Egli (1991) há consenso quanto à influência do vigor sobre a emergência das plântulas e o desenvolvimento inicial das plantas, mas não se conhece perfeitamente até que ponto esses efeitos se estendem até estados fenológicos mais avançados e afetam a produção da cultura. Desse modo, os estudos dos efeitos do vigor das sementes sobre o desempenho das plantas, deveriam analisar separadamente as diversas etapas do desenvolvimento das plantas, levando em consideração que os órgãos colhidos são diferentes entre espécies, de acordo com a finalidade a que se destinam (Burris, 1976).
Portanto, verifica-se a predominância de informações focalizando a influência do vigor das sementes durante os estádios iniciais de desenvolvimento das plantas. Nesse contexto, Lingegowda e Andrews (1973), observaram que sementes de nabo com menor potencial fisiológico originaram menor emergência de plântulas, plantas com menor acúmulo de matéria seca de folhas e raízes de menor diâmetro e comprimento. Efeitos favoráveis do vigor sobre o desenvolvimento inicial das plantas, também foram verificados em alface (Franzin et al., 2003), cebola (Rodo e Marcos Filho, 2003), rabanete (Marcos Filho e Kikuti, 2006) e couve-flor (Kikuti e Marcos Filho, 2007), mas esses efeitos não se estenderam até a produção comercial, em contrate às observações efetuadas por Powel et al. (1991), com brássicas.

Diante do exposto, o presente trabalho foi realizado com o objetivo de avaliar a influência do vigor de diferentes lotes de sementes de rúcula, cultivares Cultivada e Folha Larga, sobre o desempenho das plantas em campo.

\section{MATERIAL E MÉTODOS}

O trabalho foi conduzido no Laboratório de Análise de Sementes e na Horta Experimental em Alagoinha (5 $5^{\circ}$ 3'60" S; $37^{\circ} 24^{\prime} 18^{\prime \prime}$ W) do Departamento de Ciências Vegetais da Universidade Federal Rural do Semiárido (UFERSA), em Mossoró-RN, durante o período de março de 2008 a outubro de 2009. Para isso, utilizaram-se duas cultivares de rúcula, Folha Larga e Cultivada, cada uma representada por quatro lotes. As sementes foram cedidas por ISLA Sementes Ltda (em Porto Alegre, RS). Após a recepção, os lotes foram homogeneizados, acondicionados em embalagens de papel kraft e armazenados em ambiente controlado $\left(20{ }^{\circ} \mathrm{C}\right.$ e $55 \%$ de umidade relativa do ar) durante todo o período experimental.

Para a avaliação do potencial fisiológico foram conduzidos os testes de germinação, primeira contagem de germinação, classificação do vigor de plântulas, condutividade elétrica, envelhecimento acelerado, deterioração controlada, emergência de plântulas em campo, além da determinação do grau de umidade.

Grau de umidade: utilizou-se o método da estufa a $105^{\circ} \mathrm{C} \pm 3{ }^{\circ} \mathrm{C}$, durante 24 horas de acordo com as Regras para Análise de Sementes - RAS (Brasil, 1992). Para isso, utilizaram-se duas subamostras com aproximadamente 4,0 g de sementes para cada lote. Os resultados foram expressos em percentagem média (base úmida) por lote. 
Germinação: conduzido com quatro repetições de 50 sementes por lote, distribuídas sobre duas folhas de papel mata-borrão, previamente umedecidas com quantidade de água equivalente a 2,5 vezes o peso do papel seco, e colocadas no interior de caixas plásticas transparentes $(11,5 \times 11,5 \times 3,5 \mathrm{~cm})$, a $20{ }^{\circ} \mathrm{C}$. As avaliações foram realizadas aos quatro (primeira contagem) e sete dias após a semeadura e os resultados expressos em percentagem média de plântulas normais para cada lote (Brasil, 1992).

Classificação do vigor de plântulas: segui-se a metodologia proposta por Nakagawa (1999). Na data correspondente à da primeira contagem (quarto dia) do teste de germinação, as plântulas normais bem desenvolvidas e morfologicamente perfeitas foram retiradas, computadas e classificadas como "fortes" (vigorosas). $\mathrm{Na}$ data correspondente à contagem final (sétimo dia), as plântulas remanescentes foram avaliadas como normais ou anormais. As normais foram classificadas como "fortes" ou "fracas". Foram consideradas como plântulas normais "fracas" aquelas que apresentaram algum problema em sua estrutura ou lesão, mas insuficientes para caracterizálas como anormais. Os resultados foram expressos em percentagem média de plântulas "fortes".

Condutividade elétrica: conduzida de acordo com metodologia proposta por Alves e Sá (2009), utilizandose com quatro repetições de 50 sementes para cada lote, contadas e pesadas $(0,001 \mathrm{~g})$, colocadas em copos de plástico contendo $50 \mathrm{~mL}$ de água destilada e mantidas a $25{ }^{\circ} \mathrm{C}$ durante quatro horas. As leituras foram realizadas em condutivímetro Digimed DM-31 e, os resultados expressos em $\mu \mathrm{S} . \mathrm{cm}^{-1} \cdot \mathrm{g}^{-1}$ de semente.

Envelhecimento acelerado: conduziu-se de acordo com o proposto por Goulart e Tillmann (2007), em caixas de plástico transparente $(11,5 \times 11,5 \times 3,5 \mathrm{~cm})$, como compartimentos individuais (mini-câmaras), possuindo em seu interior suportes para apoio de uma tela metálica, onde as sementes (9 $\mathrm{g}$ por lote) foram distribuídas em camada única. No interior de cada caixa foram adicionados $40 \mathrm{~mL}$ de água destilada; as caixas foram mantidas em câmara a $41{ }^{\circ} \mathrm{C}$, por 48 horas. Decorrido esse período de envelhecimento, quatro subamostras de 50 sementes de cada lote foram colocadas para germinar seguindo a mesma metodologia utilizada para o teste de germinação. A avaliação foi realizada aos quatro dias após a semeadura, computando-se a percentagem de plântulas normais (Brasil, 1992).

Deterioração controlada: primeiramente, o grau de umidade foi ajustado artificialmente para $20 \%$, através do método da atmosfera úmida (Rossetto et al., 1995). Para tanto, foram colocados $40 \mathrm{~mL}$ de água destilada em caixas de plástico transparente $(11,5 \times 11,5 \times 3,5 \mathrm{~cm})$ com suporte para apoio de uma tela metálica e, sobre esta, distribuídas amostras de aproximadamente 5,0 $\mathrm{g}$ de sementes, em camada uniforme. As caixas foram tampadas e colocadas em germinador a $20{ }^{\circ} \mathrm{C}$. Durante o umedecimento artificial, o grau de umidade de cada amostra foi monitorado mediante pesagens sucessivas, até se obter o valor desejado ( $20 \%$ de água). Uma vez obtido esse grau de umidade, cada amostra foi colocada em embalagem aluminizada, hermeticamente fechada e mantida por cinco dias em ambiente controlado (18-20 ${ }^{\circ} \mathrm{C}$ ), com o objetivo de uniformizar a distribuição de água no interior das sementes. Em seguida, as amostras foram colocadas em banho-maria a $41{ }^{\circ} \mathrm{C}$, por 24 horas (Goulart e Tillmann, 2007). Após esse período, determinouse o grau de umidade das sementes pelo o método da estufa $\left(105 \pm 3{ }^{\circ} \mathrm{C}\right)$ (Brasil, 1992) e conduzido teste de germinação, da maneira já descrita. A avaliação foi realizada aos quatro dias após a semeadura, registrandose a percentagem média de plântulas normais por lote (Brasil, 1992).

Emergência de plântulas: quatro repetições de 50 sementes foram semeadas em canteiros no espaçamento de $0,10 \mathrm{~m} \times 0,20 \mathrm{~m}$, fazendo uso de irrigação quando necessário. A avaliação foi realizada aos 15 dias após a semeadura, computando-se as porcentagens de plântulas emergidas (Nakagawa, 1994).

Nos testes de laboratório, utilizaram-se quatro repetições em delineamento inteiramente casualizado, separadamente para cada cultivar e teste conduzido, avaliando-se os efeitos de lotes. As médias foram comparadas pelo teste de Tukey $(\mathrm{p}<0,05)$.

As avaliações da emergência de plântulas em campo foram realizadas no sistema de semeadura direta, após preparo convencional dos canteiros $(1,10 \times 10,60 \mathrm{~m})$. Com base na análise química do solo, a adubação química não foi necessária porque o solo apresentava níveis adequados de nutrientes. Em seguida, realizou-se a semeadura, colocando-se três sementes por cova. Visando obter estande uniforme de 20 plantas por metro linear de sulco, para cada lote e cultivar, procedeu-se o desbaste aos 10 dias após a semeadura (Filgueira, 2008).

Cada unidade experimental foi constituída por seis linhas contendo dez plantas, no espaçamento de 0,20 $\mathrm{m}$ entre linha e $0,10 \mathrm{~m}$ entre plantas; a área útil de cada parcela foi representada pelas quatro linhas centrais, 
compreendendo $0,64 \mathrm{~m}^{2}$. Nesta, utilizaram-se quatro linhas centrais como área útil, excluindo-se as plantas da bordadura. As irrigações foram diárias e a capina realizada semanalmente.

As avaliações do desenvolvimento vegetativo foram realizadas aos 15, 22, 30 e 36 dias após a semeadura, coletando-se 10 plantas por parcela e determinando-se a altura de plantas, número médio de folhas e massa de matéria seca da parte aérea da planta.

Altura de planta: avaliada em centímetros, mediante a tomada da medida entre o colo e a folha de maior comprimento.

Numero médio de folhas: obtido mediante a contagem do número de folhas das plantas amostradas.

Massa da matéria seca da parte aérea da planta: foi determinada para cada época de avaliação. Para isso, a parte aérea foi cortada na região do colo, embalada em saco de papel e submetida à secagem em estufa a $70^{\circ} \mathrm{C}$, até peso constante, seguida por pesagem em balança analítica $(0,001 \mathrm{~g})$.

A análise estatística das avaliações no campo foi realizada de acordo com delineamento de blocos ao acaso, testando os efeitos dos lotes separadamente para cada lote e cultivar. As médias foram comparadas pelo teste de Tukey $(\mathrm{p}<0,05)$.

\section{RESULTADOS E DISCUSSÃO}

Os resultados da avaliação do potencial fisiológico inicial dos lotes de sementes de rúcula, mediante os testes de germinação, primeira contagem de germinação, classificação do vigor de plantas, envelhecimento acelerado, deterioração controlada, condutividade elétrica e emergência de plântulas em campo, encontram-se na Tabela 1.

TABELA 1. Valores médios de germinação (G), primeira contagem de germinação (PCG), classificação do vigor de plântulas (CVP), envelhecimento acelerado (EA), deterioração controlada (DC), condutividade elétrica (CE) e emergência de plântulas (EP) de diferentes lotes de sementes de rúcula, cv. Cultivada e Folha Larga.

\begin{tabular}{ccccccccc}
\hline Cultivar & Lotes & G $(\%)$ & PCG $(\%)$ & CVP $(\%)$ & EA $(\%)$ & DC $(\%)$ & CE $\mu$ S.cm - $^{-1} \mathrm{~g}^{-1}$ & EP (\%) \\
\hline \multirow{5}{*}{ Cultivada } & 1 & $84 \mathrm{~b}$ & $81 \mathrm{a}$ & $42 \mathrm{~b}$ & $59 \mathrm{~b}$ & $79 \mathrm{~b}$ & $384,52 \mathrm{a}$ & $71 \mathrm{a}$ \\
& 2 & $98 \mathrm{a}$ & $89 \mathrm{a}$ & $64 \mathrm{a}$ & $80 \mathrm{a}$ & $90 \mathrm{a}$ & $397,50 \mathrm{a}$ & $58 \mathrm{a}$ \\
& 3 & $95 \mathrm{a}$ & $87 \mathrm{a}$ & $66 \mathrm{a}$ & $76 \mathrm{ab}$ & $91 \mathrm{a}$ & $378,27 \mathrm{a}$ & $70 \mathrm{a}$ \\
& 4 & $95 \mathrm{a}$ & $88 \mathrm{a}$ & $65 \mathrm{a}$ & $76 \mathrm{ab}$ & $90 \mathrm{a}$ & $324,30 \mathrm{a}$ & $68 \mathrm{a}$ \\
\hline \multirow{5}{*}{ Folha Larga } & C.V.(\%) & 11,84 & 8,6 & 13,52 & 11,83 & 5,38 & 14,04 & 12,39 \\
\hline & 5 & $99 \mathrm{a}$ & $98 \mathrm{a}$ & $68 \mathrm{a}$ & $79 \mathrm{a}$ & $91 \mathrm{a}$ & $326,48 \mathrm{~b}$ & $53 \mathrm{a}$ \\
& 6 & $95 \mathrm{a}$ & $93 \mathrm{~b}$ & $57 \mathrm{a}$ & $80 \mathrm{a}$ & $89 \mathrm{a}$ & $389,28 \mathrm{ab}$ & $53 \mathrm{a}$ \\
& 7 & $96 \mathrm{a}$ & $94 \mathrm{ab}$ & $66 \mathrm{a}$ & $79 \mathrm{a}$ & $87 \mathrm{a}$ & $307,28 \mathrm{~b}$ & $70 \mathrm{a}$ \\
& 8 & $97 \mathrm{a}$ & $95 \mathrm{ab}$ & $66 \mathrm{a}$ & $77 \mathrm{a}$ & $88 \mathrm{a}$ & $438,33 \mathrm{a}$ & $64 \mathrm{a}$ \\
\hline
\end{tabular}

Letras distintas dentro de cada coluna diferem entre si pelo teste de Tukey $(\mathrm{p}<0,05)$.

Os lotes das duas cultivares apresentaram percentagens médias de plântulas normais superiores à mínima estabelecida para comercialização de sementes de rúcula,ou seja, $80 \%$ de germinação. O lote 1 da cultivar Cultivada apresentou comportamento inferior, diferindo estatisticamente dos lotes 2, 3 e 4 . Por outro lado, as diferenças no potencial fisiológico das sementes da cultivar Folha Larga eram estreitas e não foram detectadas pelo teste de germinação. Segundo Marcos Filho (1999a), é importante e coerente a comparação de lotes de sementes com germinações semelhantes e, de acordo com Powell (1986), preferencialmente situados na Fase I da 
curva de perda de viabilidade. Essa autora considera que a posição do lote dentro da Fase I determina seu nível de vigor. Neste estudo, todos os lotes apresentaram alto potencial fisiológico, com germinação variando entre $84 \mathrm{e}$ 99\%, e situados, portanto, na Fase I da curva de perda de viabilidade de lotes de sementes.

Com relação aos resultados da primeira contagem do teste de germinação, verifica-se que os lotes da cultivar Cultivada apresentaram comportamento semelhante aos verificados para o teste de germinação, exceto para o lote 1 que não foi apontado como de menor vigor. Já para os lotes da Folha Larga o teste de primeira contagem de germinação mostrou-se mais sensível que o de germinação, indicando os lotes 5 e 6 como os de melhor e pior desempenho, respectivamente. Embora a primeira contagem de germinação possa ser considerada um indicativo de vigor, sabe-se que a redução da velocidade da germinação não está entre os primeiros eventos do processo de deterioração de sementes (Delouche e Baskin, 1973), justificando a menor eficiência deste teste para detectar diferenças mais estreitas de vigor e o conseqüente agrupamento dos lotes. Por outro lado, Alvarenga et al. (1984) com sementes de melancia e Bhéring et al. (2000) com pepino, verificaram que o teste de primeira contagem pode ser adequado para monitorar o vigor de sementes dessas espécies.

Os testes de germinação, classificação do vigor de plântulas, envelhecimento acelerado e deterioração controlada produziram resultados semelhantes para os lotes da cultivar Cultivada; para os lotes da 'Folha Larga', esses testes não apresentaram resultados diferentes entre lotes, exceto para os testes de condutividade elétrica e primeira contagem do teste de germinação, que acusaram superioridade significativa do potencial fisiológico do lote 5 , em relação ao lote 8 . Para as duas cultivares, os resultados de emergência das plântulas em campo não apresentaram diferenças entre lotes.

A sensibilidade do teste de classificação do vigor de plantas, não foi plenamente verificada neste estudo. O lote 1 da cultivar Cultivada foi apontado como de baixo vigor, enquanto que os demais lotes apresentaram desempenho superior. Para os lotes da 'Folha Larga' não houve diferenças entre lotes. Essas observações confirmam a menor sensibilidade de parâmetros relacionados à germinação determinada em laboratório, para identificar diferenças no desempenho das sementes. Por outro lado, Goulart e Tillmann (2007), também com sementes de rúcula, cultivar Cultivada, verificaram que o teste de classificação do vigor de plantas mostrou-se eficiente na separação dos lotes em diferentes níveis de vigor.

A eficiência dos testes de envelhecimento acelerado, deterioração controlada e condutividade elétrica (Tabela 1) são amplamente relatadas na literatura tanto para as grandes culturas quanto para as hortaliças. No presente trabalho, houve confirmação de observações efetuadas por vários pesquisadores, dentre os quais Guimarães et al. (1993), com alface; Andrade et al. (1995), com cenoura; Mendonça et al. (2000), com brócolos; Rodo e Marcos Filho (2003), com cebola; Torres e Marcos Filho (2003), com melão; Bhéring et al. (2003), com melancia; Marcos Filho e Kikuti (2006), com rabanete; Ramos et al. (2004), Goulart e Tillmann (2007) e Alves e Sá (2009), com rúcula.

Os resultados da emergência de plântulas em campo, para as duas cultivares, não indicaram diferenças entre os lotes, provavelmente pelas diferenças estreitas no potencial fisiológico das sementes. Para todos os lotes, verificou-se que esse teste apresentou resultados inferiores ao encontrado para o teste de germinação. Isso ocorreu em função das condições menos favoráveis de ambiente que, normalmente, podem subestimar os resultados em campo (Marcos Filho et al., 1987). Em geral, a capacidade dos testes de laboratório para estimar o potencial de emergência das plântulas diminui à medida que as condições de ambiente se desviam das mais adequadas, tornando-se quase nula sob condições extremamente desfavoráveis (temperatura, umidade, substrato etc.).

Demodo geral, o conjunto de informações provenientes dos testes de laboratório (teste de germinação, primeira contagem de germinação, classificação do vigor de planta, envelhecimento acelerado, deterioração controlada e condutividade elétrica) não permitiu identificar, com consistência, os lotes com potenciais fisiológicos diferentes. Esse fato, provavelmente, deve-se ao fato dos lotes de sementes terem qualidade fisiológica bastante estreita. Ao mesmo tempo, constata-se a necessidade da continuidade de estudos dessa natureza para assegurar a consistência desses procedimentos.

$\mathrm{Na}$ Tabela 2, verifica-se que o grau de umidade inicial das sementes variou em 1,8 pontos percentuais (p.p.) $(5,0$ a $6,8 \%)$, valor que está dentro do limite tolerável para obtenção de resultados consistentes e não afeta as informações proporcionadas nos diferentes testes (Marcos Filho, 2005). Observa-se que o grau de umidade das sementes após, o período de envelhecimento variou em 8,8 p.p., que excede os limites toleráveis ( 3 a 4 p.p.), indicados por Marcos Filho (1999b). O grau de 
umidade das sementes atingido no teste de deterioração controlada foi uniforme entre amostras, concordando com as informações de Krzyzanowski e Vieira (1999) que o teste de deterioração controlada permite melhor controle do grau de umidade da semente e a temperatura durante o envelhecimento que o teste de envelhecimento acelerado.

TABELA 2. Grau de umidade (\%) inicial e após o teste de envelhecimento acelerado (EA) e de deterioração controlada (DC) de diferentes lotes de sementes de rúcula cv. Cultivada e Folha Larga.

\begin{tabular}{ccccc}
\hline Cultivar & Lotes & Inicial & EA & DC \\
\hline \multirow{3}{*}{ Cultivada } & 1 & 5,0 & 21,8 & 20,6 \\
& 2 & 6,6 & 28,2 & 20,8 \\
& 3 & 5,2 & 26,7 & 21,0 \\
Folha Larga & 4 & 5,3 & 26,6 & 20,9 \\
\hline & 5 & 6,6 & 27,5 & 20,4 \\
& 6 & 5,5 & 25,9 & 20,1 \\
& 7 & 6,7 & 26,6 & 20,7 \\
\end{tabular}

Os resultados referentes avaliação do desempenho das plantas no campo encontram-se nas Tabelas 3, 4 e 5 . Para as duas cultivares não foram constatadas diferenças significativas entre os lotes para os parâmetros avaliados (altura, número de folhas e massa da matéria seca da parte aérea da planta), para todas as épocas de avaliação.

Essa semelhança encontrada no desempenho dos lotes das duas cultivares pode ser resultante da não existência de diferenças acentuadas no potencial fisiológico das sementes, constatadas tanto nos testes de laboratório quanto no desempenho das plântulas em campo. Em função desse estreitamento, é provável que as variações do vigor das sementes não tenham sido suficientemente amplas para se refletir durante o desempenho das plantas em campo, mesmo no desenvolvimento inicial das plantas. Portanto, não é supreendente o fato de que lotes de sementes com elevado potencial fisiológico realmente originem plantas com desempenho semelhante.

TABELA 3. Resultados médios da altura de plantas de diferentes lotes de sementes de rúcula, cv. Cultivada e Folha Larga.

\begin{tabular}{lccccc}
\hline \multirow{3}{*}{ Cultivar } & Lote & \multicolumn{5}{c}{ Épocas de avaliação (dias) } \\
\cline { 2 - 5 } & 1 & 15 & 22 & 30 & 36 \\
\cline { 2 - 5 } Cultivada & $6,57 \mathrm{a}$ & $9,47 \mathrm{a}$ & $15,90 \mathrm{a}$ & $19,75 \mathrm{a}$ \\
& 2 & $6,75 \mathrm{a}$ & $10,20 \mathrm{a}$ & $16,45 \mathrm{a}$ & $21,00 \mathrm{a}$ \\
& 3 & $5,95 \mathrm{a}$ & $10,10 \mathrm{a}$ & $15,60 \mathrm{a}$ & $19,00 \mathrm{a}$ \\
& 4 & $5,00 \mathrm{a}$ & $9,65 \mathrm{a}$ & $17,10 \mathrm{a}$ & $21,75 \mathrm{a}$ \\
\hline \multirow{3}{*}{ Folha larga } & C.V.(\%) & 25,44 & 6,72 & 10,27 & 13,16 \\
& 5 & $6,92 \mathrm{a}$ & $9,57 \mathrm{a}$ & $15,95 \mathrm{a}$ & $20,25 \mathrm{a}$ \\
& 6 & $6,57 \mathrm{a}$ & $9,87 \mathrm{a}$ & $16,17 \mathrm{a}$ & $21,75 \mathrm{a}$ \\
& 7 & $6,40 \mathrm{a}$ & $9,35 \mathrm{a}$ & $15,95 \mathrm{a}$ & $18,00 \mathrm{a}$ \\
& 8 & $6,42 \mathrm{a}$ & $10,45 \mathrm{a}$ & $16,95 \mathrm{a}$ & $20,50 \mathrm{a}$ \\
\hline
\end{tabular}

Letras distintas dentro de cada coluna diferem entre si pelo teste de Tukey $(p<0,05)$. 
TABELA 4. Resultados médios do número de folhas por plantas para os diferentes lotes de sementes de rúcula, cv. Cultivada e Folha Larga.

\begin{tabular}{cccccc}
\hline \multirow{2}{*}{ Cultivar } & Lote & \multicolumn{4}{c}{ Épocas de avaliação (dias) } \\
\cline { 2 - 5 } & 1 & $5,25 \mathrm{a}$ & 15 & 30 & 36 \\
\hline \multirow{4}{*}{ Cultivada } & 2 & $5,50 \mathrm{a}$ & $7,50 \mathrm{a}$ & $15,00 \mathrm{a}$ & $21,50 \mathrm{a}$ \\
& 3 & $5,00 \mathrm{a}$ & $8,00 \mathrm{a}$ & $16,00 \mathrm{a}$ & $21,25 \mathrm{~b}$ \\
& 4 & $5,25 \mathrm{a}$ & $8,25 \mathrm{a}$ & $15,75 \mathrm{a}$ & $21,50 \mathrm{a}$ \\
& C.V.(\%) & 8,98 & 11,77 & 11,5 & $26,00 \mathrm{a}$ \\
\hline \multirow{3}{*}{ Folha larga } & 5 & $5,50 \mathrm{a}$ & $8,00 \mathrm{a}$ & $14,00 \mathrm{a}$ & $25,25 \mathrm{a}$ \\
& 6 & $5,00 \mathrm{a}$ & $7,00 \mathrm{a}$ & $14,50 \mathrm{a}$ & $24,25 \mathrm{a}$ \\
& 7 & $5,00 \mathrm{a}$ & $8,00 \mathrm{a}$ & $13,75 \mathrm{a}$ & $22,25 \mathrm{a}$ \\
& 8 & $5,75 \mathrm{a}$ & $8,00 \mathrm{a}$ & $14,50 \mathrm{a}$ & $25,00 \mathrm{a}$ \\
\hline
\end{tabular}

Letras distintas dentro de cada coluna diferem entre si pelo teste de Tukey $(p<0,05)$.

TABELA 5. Resultados médios da massa da matéria seca da parte aérea da planta para os diferentes lotes de sementes de rúcula, cv. Cultivada e Folha Larga.

\begin{tabular}{lccccc}
\hline \multirow{3}{*}{ Cultivar } & \multirow{4}{*}{ Lotes } & \multicolumn{4}{c}{ Épocas de avaliação (dias) } \\
\cline { 3 - 6 } & & & 22 & 30 & 36 \\
\cline { 2 - 5 } Cultivada & 1 & $52,50 \mathrm{a}$ & $222,50 \mathrm{a}$ & $1267,50 \mathrm{a}$ & $3272,50 \mathrm{a}$ \\
& 2 & $61,75 \mathrm{a}$ & $315,00 \mathrm{a}$ & $1412,50 \mathrm{a}$ & $3555,00 \mathrm{a}$ \\
& 3 & $55,25 \mathrm{a}$ & $300,00 \mathrm{a}$ & $1270,00 \mathrm{a}$ & $3307,50 \mathrm{a}$ \\
& 4 & $67,25 \mathrm{a}$ & $300,00 \mathrm{a}$ & $1872,50 \mathrm{a}$ & $4477,50 \mathrm{a}$ \\
\hline \multirow{4}{*}{ Folha larga } & C.V. $(\%)$ & 20,09 & 21,15 & 25,45 & 25,74 \\
& 5 & $59,00 \mathrm{a}$ & $292,00 \mathrm{a}$ & $1425,00 \mathrm{a}$ & $3802,50 \mathrm{a}$ \\
& 6 & $51,50 \mathrm{a}$ & $270,00 \mathrm{a}$ & $1260,00 \mathrm{a}$ & $4192,50 \mathrm{a}$ \\
& 7 & $51,75 \mathrm{a}$ & $265,00 \mathrm{a}$ & $1335,00 \mathrm{a}$ & $3487,50 \mathrm{a}$ \\
& 8 & $62,25 \mathrm{a}$ & $362,50 \mathrm{a}$ & $1510,00 \mathrm{a}$ & $4260,00 \mathrm{a}$ \\
\hline
\end{tabular}

Letras distintas dentro de cada coluna diferem entre si pelo teste de Tukey $(\mathrm{p}<0,05)$.

Desta maneira, os resultados aqui encontrados, permitem enfatizar que o uso de sementes vigorosas é justificável para assegurar o estabelecimento adequado do estande, mesmo que não haja manifestação de diferenças do desempenho inicial das plantas.

\section{CONCLUSÕES}

Variações estreitas do vigor de lotes de sementes de rúcula com germinação superior à mínima estabelecida para comercialização não são suficientes para influenciar significativamente o desempenho das plantas em campo.

\section{AGRADECIMENTOS}

Os autores agradecem à empresa ISLA Sementes Ltda, na pessoa da Eng. Agrônoma Juliana R. Trinca, por ceder as sementes utilizadas neste experimento. 


\section{REFERÊNCIAS}

ALVARENGA, E.M.; SILVA, R.F.; ARAÚJO, E.F.; CARDOS, A.A. Influência da idade e armazenamento póscolheita dos frutos na qualidade de sementes de melancia. Horticultura Brasileira, v.2, n.2, p.5-8, 1984.

ALVES, C.Z.; SÁ, M.E. Teste de condutividade elétrica na avaliação do vigor de sementes de rúcula. Revista Brasileira de Sementes, v.31, n.1, p.203-215, 2009.

ANDRADE, R.N.; SANTOS, D.S.B.; SANTOS FILHO, B.G.; MELLO, V.D.C. Correlação entre testes de vigor em sementes de cenoura armazenadas por diferentes períodos. Pesquisa Agropecuária Gaúcha, v.1, n.2, p.153-162, 1995.

BHÉRING, M.C.; DIAS, D.C.F.S.; GOMES, J.M.; BARROS, D.I. Métodos para avaliação do vigor de sementes de pepino. Revista Brasileira de Sementes, v.22, n.2, p.171-175, 2000.

BHÉRING, M.C.; DIAS, D.C.F.S.; BARROS, D.I.; DIAS, L.A.S.;TOKUHISA, D. Avaliação do vigor de sementes de melancia (Citrullus lunatus Schrad.) pelo teste de envelhecimento acelerado. Revista Brasileira de Sementes, v.25, n.2, p.1-6, 2003.

BRASIL. Ministério da Agricultura e Reforma Agrária. Secretaria Nacional de Defesa Agropecuária. Departamento Nacional de Defesa Vegetal. Coordenação de Laboratório Vegetal. Regras para análise de sementes. Brasília, DF, 1992.365p.

BURRIS, J.S. Seed/seedling vigor and field performance. Journal of Seed Technology, v.1, n.2, p.58-74, 1976.

DELOUCHE, J.C.; BASKIN, C.C. Accelerated aging techniques for predicting the relative storability of seed lots. Seed Science and Technology, v.1, n.2, p. 427-452, 1973.

FILGUEIRA, F.A.R. Novo manual de olericultura: agrotecnologia moderna na produção e comercialização de hortaliças. 3.ed. Viçosa: UFV, 2008. p.402.

FRANZIN, S.M.; MENEZES, N.L.; GARCIA，D.Z.; SANTOS, O.S. Efeitos do vigor das sementes sobre a formação de mudas de alface. Informativo ABRATES, v.13, n.3, p.305, 2003.

GOULART, L.S.; TILLMANN, M.A.A. Vigor de sementes de rúcula (Eruca sativa L.) pelo teste de deterioração controlada. Revista Brasileira de Sementes, v.29, n.2, p.179-186, 2007.

GUIMARÃES, J.R.M.; MALAVASI, M.M.; LOPES, H.M.
Definição do protocolo do teste de condutividade elétrica para avaliação do vigor de sementes de alface (Lactuca sativa L.). Informativo ABRATES, v.3, n.3, p.138, 1993.

KIKUTI, A.L.P.; MARCOS FILHO, J. Potencial fisiológico de sementes de couve-flor e desempenho das plantas em campo. Revista Brasileira de Sementes, v.29, n.1, p.107113, 2007.

KRZYZANOWSKI, F.C.; VIEIRA, R.D. Deterioração controlada. In: KRZYZANOWSKI, F.C.; VIEIRA, R.D.; FRANÇA NETO, J.B. (Ed.). Vigor de sementes: conceitos e testes. Londrina: ABRATES, 1999. cap.6, p.1-8.

LINGEGOWDA, H.; ANDREWS, H. Effects of size in cabbage and turnip on performance of seeds, seedlings and plants. Procceedings of the Association of Official Seed Analysts, v.63, p.117-125, 1973.

MARCOS FILHO, J. Testes de vigor: importância e utilização. In: KRZYZANOWSKI, F.C.; VIEIRA, R.D.; FRANÇA NETO, J.B. (Ed.). Vigor de sementes: conceitos e testes. Londrina: ABRATES, 1999a. cap.1, p.1-21.

MARCOS FILHO, J. Fisiologia de sementes de plantas cultivadas. Piracicaba: FEALQ, 2005. 495p.

MARCOS FILHO, J. Teste de envelhecimento acelerado. In: KRZYZANOWSKI, F.C.; VIEIRA, R.D., FRANÇA NETO, J.B. (Ed.). Vigor de sementes: conceitos e testes. Londrina: ABRATES, 1999b. cap.3, p.1-24.

MARCOS FILHO, J.; KIKUTI, A.L.P. Vigor de sementes de rabanete e desempenho de plantas no campo. Revista Brasileira de Sementes, v.28, n.3, p.44-51, 2006.

MARCOS FILHO, J.; CICERO, S.M.; SILVA, W.R. Avaliação da qualidade de sementes. Piracicaba: FEALQ, 1987. 320p.

MENDONÇA, E.A.F., RAMOS, N.P., FESSEL, S.A. Adequação da metodologia do teste de deterioração controlada para sementes de brócolis (Brassica oleracea L. - var. Itálica). Revista Brasileira de Sementes, v.25, n.1, p.18-24, 2003.

MENDONÇA, E.A.F.; RAMOS, N.P.; FESSEL, S.A.; SADER, R. Teste de deterioração controlada em sementes de brócolis. Revista Brasileira de Sementes, v.22, n.2, p.280-287, 2000.

NAKAGAWA, J. Testes de vigor baseados na avaliação das plântulas. In: VIEIRA, R.D.; CARVALHO, N.M. (Ed.). Testes de vigor em sementes. Jaboticabal: Funep, 1994, p.48-85.

NAKAGAWA, J. Testes de vigor baseados na avaliação 
de plântulas. In: KRZYZANOWSKI, F.C.; VIEIRA, R.D.; FRANÇA NETO, J.B. (Ed.). Vigor de sementes: conceitos e testes. Londrina: ABRATES, 1999. cap.2, p.1-23.

POWELL, A.A. Cell membranes and seed leachate conductivity in relation to the quality of seed for sowing. Journal of Seed Technology, v.10, n.2, p.81-100, 1986.

POWELL, A.A.; THORNTON, J.M.; MITCHELL, A. Vigour differences in brassica seed and their significante to emergence and seedling variability. Journal of Agricultural Science, v.116, n.3, p.369-373, 1991.

RAMOS, N.P.; FLOR, E.P.; MENDONÇA, E.A. F.; MINAMI, K. Envelhecimento acelerado em sementes de rúcula (Eruca sativa L.). Revista Brasileira de Sementes, v.26, n.1, p.98-103, 2004.
RODO, M.A.B.; MARCOS FILHO, J. Onion seed vigor in relation to plant growth and yield. Horticultura Brasileira, v.21, n.2, p.220-226, 2003.

ROSSETO, C.A.V.; FERNANDEZ, E.M.; MARCOS FILHO, J. Metodologias de ajuste do grau de umidade e comportamento das sementes de soja no teste de germinação. Revista Brasileira de Sementes, v.17, n.1, p.171-178, 1995.

TeKRONY, D.M.; EGLI, D.B. Relationship of sed vigor to crop yield. Crop Science, v.31, n.3, p.816-822, 1991.

TORRES, S.B. MARCOS FILHO, J. Accelerated aging of melon seeds. Scientia Agricola, v.60, n.1, p.77-82, 2003. 